\title{
Receive your brand new chair in nine weeks
}

Not only have Planmeca dental chairs got all the features you want, but they are also ahead of time in availability. Place an order today and you can expect your brand new chair to be delivered to your distributor in only nine weeks. Why wait when you can make the change today?

There is a choice of versatile dental chairs including the Planmeca Compact i5, designed to offer the smoothest possible workflow and stress-free dentistry. It is both sleek and elegant, whilst also allowing you to maintain an optimal ergonomic working position throughout the day.

The Planmeca Compact i Classic presents ease of use and uncompromised ergonomics in a cost-effective dental unit, making it an ideal choice for general dentistry.
Finally, the Planmeca Compact i3 is small, swift and clever, designed to simplify everyday dentistry with easy-touse external infection control procedures. It's the practical choice - a true space saver.

For more information on Planmeca dental chairs and those exceptional lead times, email marketinguk@planmeca.com, call 08005200330 or visit www.plandemo.co.uk.
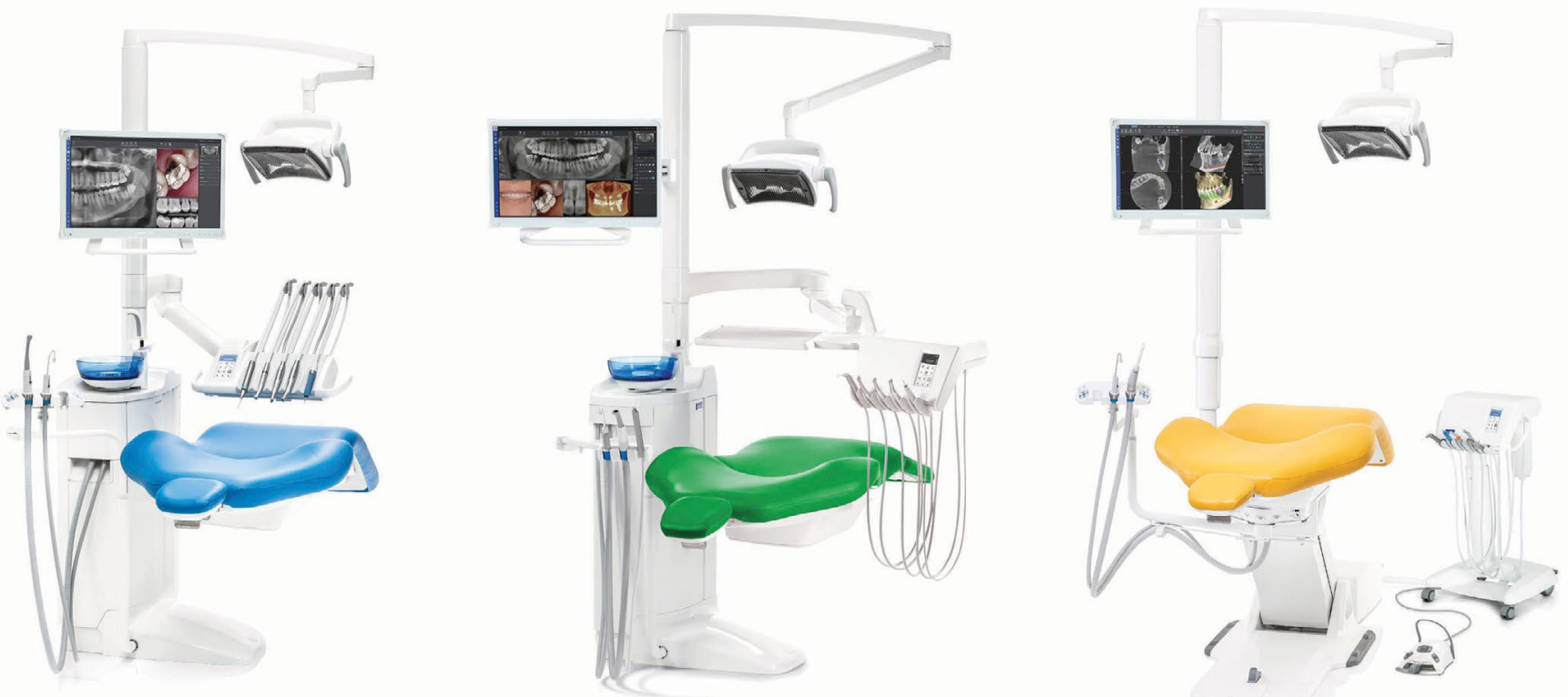

\section{Strike while the iron is hot}

With the property market booming, now is a better time than ever to sell your practice. But where to begin?

With decades of industry experience and a finger on the pulse of the current financial market, the team at practices4dentists is able to offer highquality, real-time advice that is directly tailored to the unique needs of your practice.

The team manages every aspect of the dental practice sale process, from valuation and marketing to practice visits and completion of sale agreements.

So, if you're thinking of selling, enlist the help of the experts at practices4dentists today.

For more information call 0845 3455060 or 0754 DENTIST. Email info@4dentistsgroup.com or visit www.4dentistsgroup.com.

\section{Building strong defences}

Arm \& Hammer Enamel Repair baking soda toothpaste provides the perfect formula to help patients combat acid erosion, and maintain strong and healthy teeth.

We know that acid attack and erosion can be a losing battle for some patients. The clinically proven baking soda and Liquid Calcium formula of Enamel Repair Toothpaste sets up the perfect defence by filling in tooth crevices and restoring enamel surfaces in five days, offering unrivalled protection.

To give your patients a helping hand in tackling acid erosion and building a strong and healthy mouth, look no further than Arm \& Hammer Enamel Repair baking soda toothpaste.

For more information about the carefully formulated Arm \& Hammer toothpaste range, visit https://www.armandhammer.co.uk/ or email: ukenquiries@churchdwight.com.

Arm \& Hammer oral healthcare products are available at Boots, Superdrug, Sainsbury's, Tesco, Asda and Morrisons throughout the UK.

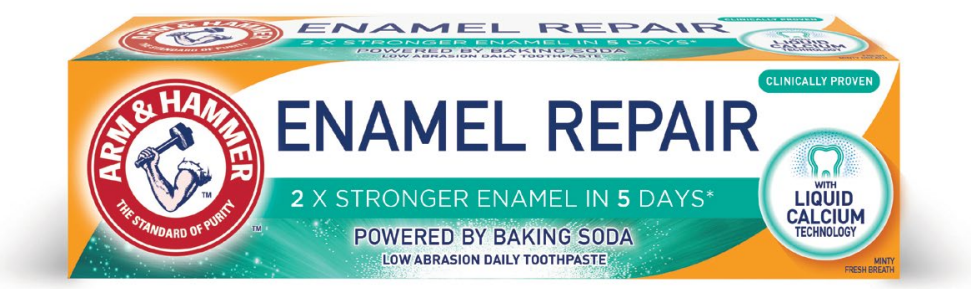

